\title{
The Great British Drill Off is open for applications
}

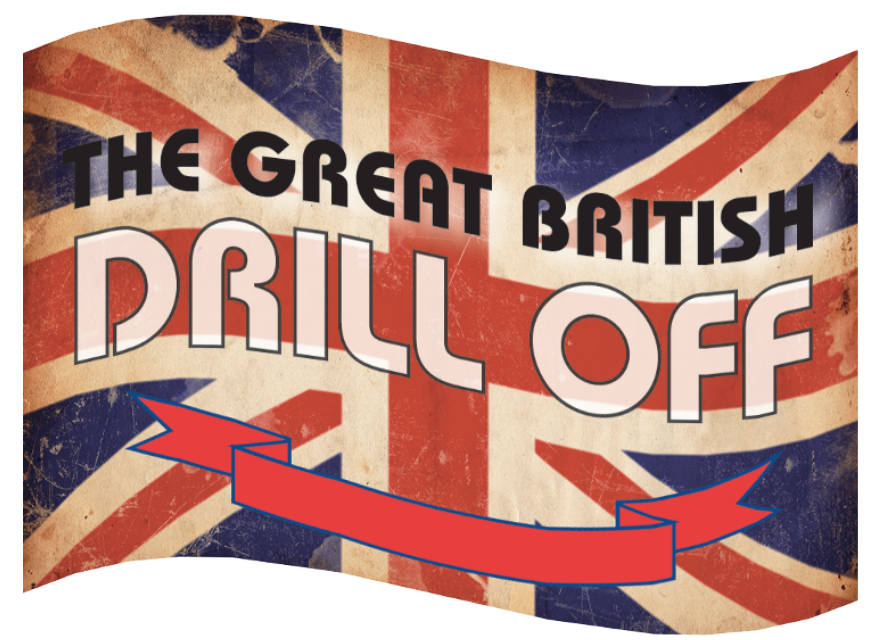

In exciting news for 2019, Channel 6 has announced the launch of a new programme The Great British Drill Off. Programme makers Fluoride Productions have confirmed that 12 dentists will be chosen to take part in the pilot series and applications are encouraged from all GDC-registered dentists.

Over a series of ten episodes, the participating dentists will face challenges each week in the form of: 'Signature

Treatment Plans', 'The Technical', and finally, the all-important 'Smilemaker' task.

Each week will have a different theme with the first three already revealed: 'Extreme Endo', 'USA Smiles', and 'MI Magic'.
It is rumoured that the final will involve dealing with 'Impossible Patients under the 2006 NHS Contract' - sure to provide a challenge to even the most experienced healthcare professional.

Participants will be provided with two 'Referral Routes' - a joker card of sorts allowing them to refer to resident specialists, but the chosen dentists will be required to work in dental teams supplied by the production company for each challenge and cannot bring their own teams with them.

The presenters are yet to be revealed, but the judges have been announced as Prue Teeth and Paul Hollywoodsmile.

Do you have what it takes to win The Great British Drill Off? Enter online here at: www.flourideproductions.com/channel 6/ GBDOapplications2019.

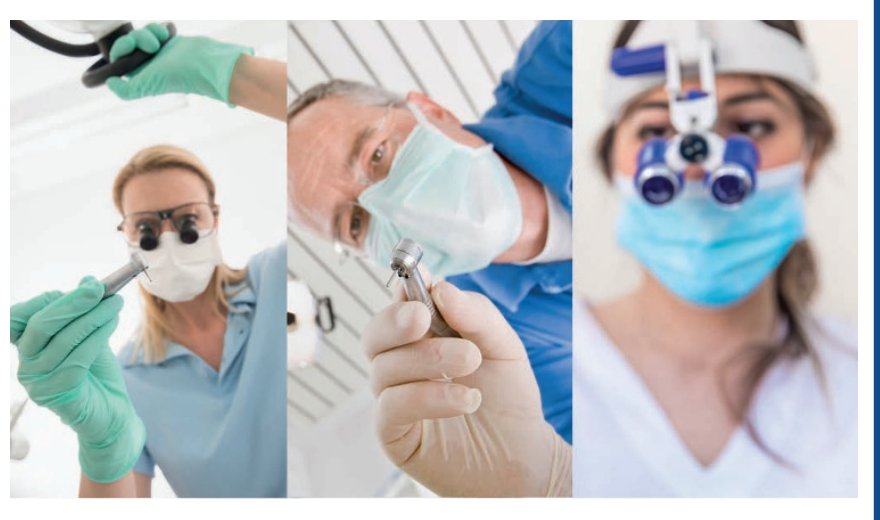

\section{New dictionary launched}

With email and digital communication now being so widespread and with English being stretched into new alternative meanings and nuances, an innovative dental and medical dictionary has been published for the internet age.

The British Dental Journal has been granted exclusive access to this new lexicon and here are some examples of the re-defined terms:

Aspirator: dental team member aiming high

AUG: the missing bit of UST

Autoimmunity: cycling

Bonding: a very good French doorbell

Cardiology: the study of zip-up jumpers

Citanest: where to place a birdbox

Condyles: nuisance phone calls from fraudsters

Cuspal: a friend with whom you share swear words

Disclosing solution: the method by which a spy is debriefed

Elevator: daughter of Mrs and Mrs Vator
Fixed appliance: built-in autoclave

Intercellular communication: banging on water pipes in prisons

Lip retraction: denial of Botox treatment

Mottling: the verb to mottle

Non-working side: strikers

Object to film distance: size of cinema car park

Pericoronitis: an award for the best pear-cider

Quicklime: a speedy addition to a 1960s pint of lager

Random clinical trial: GDC disciplinary hearing

Ridge augmentation: garden design in the Cotswolds

Rubber dam: a curse that something is not metallic

Silicone: ridiculous traffic bollard across a motorway

Stress-breaker: wine

Study models: naked people observed by artists

Transfusion: main course meal of mixed ingredients cooked by a gender re-assigned chef

WHO Geneva: science-fiction Doctor visiting Switzerland

Xerostomia: a small tropical country with no natural water supply. 